NASZA DERMATOLOGIA Online OUR DERMATOLOGY Online

Source of Support: Nil

Competing Interests: None

\section{CLASSIC KAPOSI'S SARCOMA: A RARE CASE WITH UNUSUAL PRESENTATION}

\author{
Sanjay N. Agrawal, Anuprita A. Rawal, Subodhkumar D. Jane \\ Department of Dermatology, Dr. Panjabrao Deshmukh Memorial Medical College, \\ Amravati, Maharashtra, India \\ Corresponding author: Dr. Subodhkumar D. Jane \\ dr.subodhjane86@gmail.com
}

\begin{abstract}
A 32 years old female presented with a single asymptomatic lesion on right thigh since 5 years. On examination, a single ill defined, irregular hyperpigmented plaque was present on medial aspect of right thigh. The plaque was firm in consistency and was non-tender. No scaling was evident. Clinically a differential diagnosis of Hansen's disease, lupus vulgaris and deep fungal infection were made. The histopathology interestingly showed features suggestive of Kaposi's sarcoma. The patient was HIV negative and otherwise completely asymptomatic.
\end{abstract}

Key words: Asymptomatic plaque; Kaposi’s sarcoma; Non-HIV

Cite this article:

Sanjay N. Agrawal, Anuprita A. Rawal, Subodhkumar D. Jane. Classic Kaposi's sarcoma: a rare case with unusual presentation. Our Dermatol Online. 2014; 5(1): $68-70$

\section{Introduction}

Kaposi's sarcoma (KS) is a multifocal, endothelial proliferation predominantly involving the skin and other organs and is associated with formation of vascular channels and proliferation of spindle-shaped cells [1]. KS is usually linked with HIV. Classic KS occurs sporadically and is seen in immunocompetent individuals and may present as bluishred or hyperpigmented papules, plaques or nodules over feet or hands with pedal edema. It is more common in male than female having ratio of 15:1 with predilection for elderly males. Four variants are known that is classical (sporadic), endemic (African), iatrogenic (immunosuppressive drugs associated) and AIDS-associated [2,3]. The histopathology depends upon the stage of KS as it progresses from the patch to plaque to nodular stage. The histopathology of plaque stage $\mathrm{KS}$ is characteristic with features of spindle-shaped cells arranged between the cleft-like spaces containing red blood cells (RBCs). In India, very few cases of Kaposi's sarcoma have been reported which were associated with HIV infection. We report a case of classic Kaposi sarcoma in an immunocompetent adult female as a very rare presentation.

\section{Case Report}

A 32 years old married female having two children presented with single asymptomatic hyperpigmented lesion on right thigh since 5 years. The lesion started as an erythematous macule which gradually increased in size and thickness to form an irregular plaque over right thigh. Throughout its course the lesion was painless and non-pruritic. There was no history of trauma, prior intake of any medication, recurrent fever, chronic cough and weight loss. Local examination showed a single well circumscribed, bluish and hyperpigmented non-scaly plaque measuring around $8-10 \mathrm{cms}$ over inner aspect of right thigh (Fig. 1). With this clinical findings differential diagnosis of lupus vulgaris, Hansen's disease and deep fungal infection were made. The sensations over the lesion were normal, peripheral nerves were not thickened and the slit skin smear test for acid fast bacilli was negative. On diascopy, there was no evidence of apple-jelly nodules with no lymphadenopathy and hepatosplenomegaly. Other systemic examinations were within normal limits. A skin punch biopsy was taken from the lesion and the histopathological examination interestingly and surprisingly showed proliferation of thin walled capillaries along the blood vessels of superficial plexus. The capillaries are arranged in clustered pattern and seen as rounded spaces filled with RBCs extending between collagen bundles (Fig. 2). Moderately dense infiltrate of lymphocytes and occasional neutrophils were present in dermis. Abundant extravasation of RBCs was seen in upper dermis along with some hemosiderin deposits (Fig. 3). Spindle cells arranged loosely in short fascicles are seen with formation of cleft like spaces containing RBCs (Fig. 4). These histopathological features were suggestive of plaque type of Kaposi's sarcoma (KS). With this histopathological diagnosis patient was retrospectively questioned and patient gave no history of chronic diarrhea, blood transfusion or any history of extra-marital sexual exposure. Her husband and both children were not having similar or other complaints. 




Figure 1. Clinical photograph showing a single well circumscribed, bluish and hyperpigmented plaque over inner aspect of right thigh.

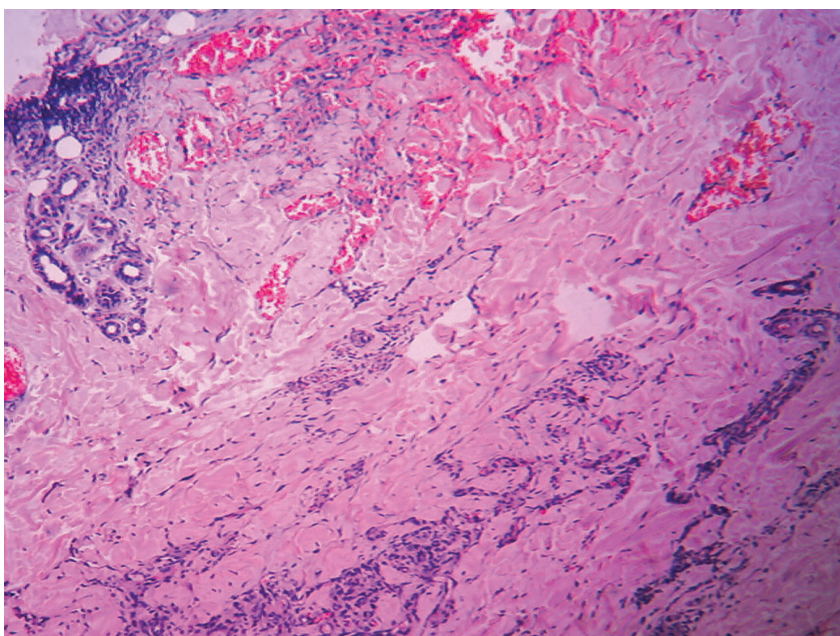

Figure 3. Histopathological features showing infiltrate of lymphocytes and occasional neutrophils and abundant extravasation of RBCs in upper dermis. (H\&E, 100x)

Her laboratory investigations revealed Complete blood count, Liver function test, Renal function test within normal limits. Serology for HBsAg and VDRL and HIV were negative. Because of lack of facilities Polymerase chain reaction (PCR) for human herpesvirus 8 (HHV-8) could not be done. Sputum for Acid Fast Bacilli (AFB) and Mantoux test were negative. Chest radiograph and ultrasonography scan of abdomen were normal.

Thus, a diagnosis of plaque type of Classical (sporadic) KS was made.

\section{Discussion}

Classic KS was originally described by Moritz Kaposi in 1872 as an 'idiopathic multipigmented sarcoma of the skin' involving endothelial cells.[4] Classic KS is rare and unassociated with

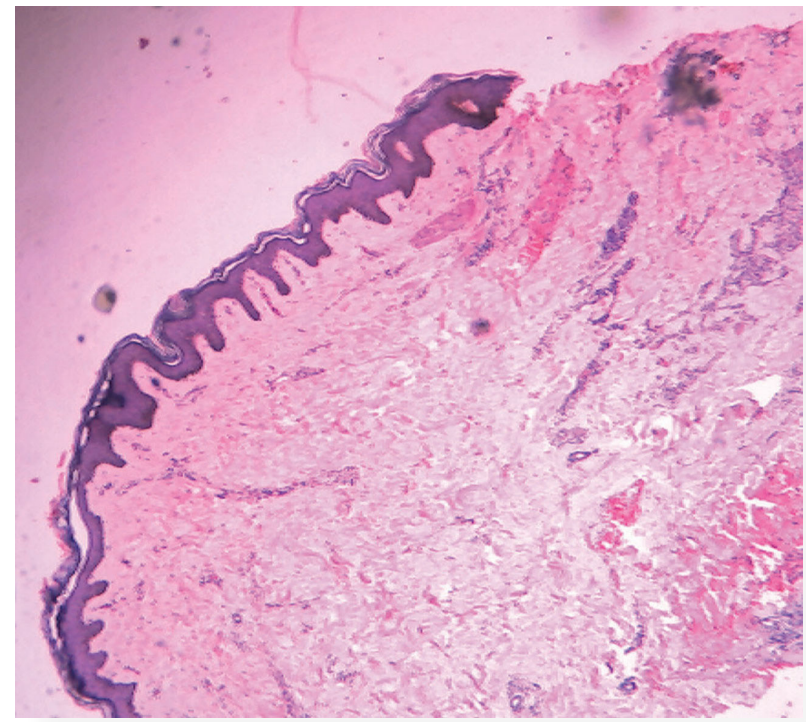

Figure 2. Histopathological features showing capillaries arranged in clustered pattern as rounded spaces filled with RBCs extending between collagen bundles. $(\mathrm{H} \&$ E, 40x)

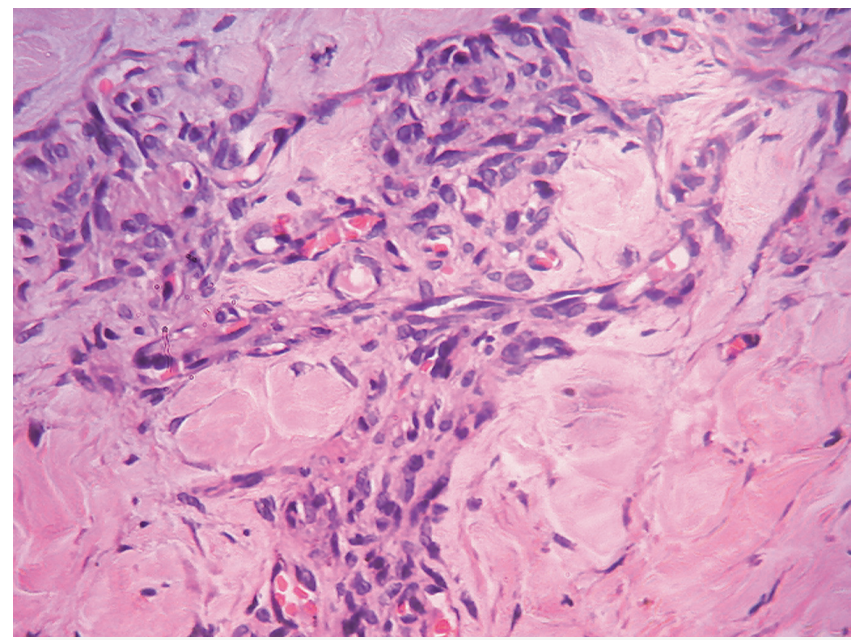

Figure 4. Histopathological features showing Spindle cells arranged loosely in short fascicles with formation of cleft like spaces containing RBCs. (H\&E, 400x)

HIV infection. An association with HHV-8 is seen. Its low prevalence in India could be attributed to low prevalence of HHV-8 $[4,5]$. It most often arises in middle-aged and elderly men of Mediterranean or Jewis descent [6]. Homosexual males are at increased risk for classic KS [7]. It usually presents as multiple firm purple blue or reddish-brown plaques and nodules typically appearing over hands and feet and progress up to arms and thighs. Commonly oedema of legs is present. In $10 \%$ of cases visceral or mucosal involvement is seen. A second non$\mathrm{KS}$ hematologic malignancy is often present in as many as 30\% cases, typically Non Hodgkin Lymphoma seen. Diagnosis is made by clinical and histopathological correlation. Treatment depends on extent and localization of lesions. It includes nonintervention, cryoablation, surgical excision, laser therapy. Till date very few cases of Classic KS have been reported. 
Our patient is a healthy young female presented with a chronic asymptomatic hyperpigmented plaque over thigh with no pedal oedema, HIV antibody negative and the characteristic histopathology of KS. So, in an asymptomatic hyperpigmented chronic plaque one should consider the differential diagnosis of classic KS. Non-HIV Kaposi's sarcoma may not be so uncommon in India and may not be suspected and hence rarely reported.

Ours could be one of the very few cases of classic KS reported from India with unusual presentation of single hyperpigmented plaque in female.

Acknowledgements-

We are grateful to Dr. Uday Khopkar, professor and head of department of dermatology, K.E.M hospital, Mumbai, India for histopathological opinion.

\section{REFERENCES}

1. Kharkar V, Gutte RM, Khopkar U, Mahajan S, Chikhalkar S. Kaposi's sarcoma: A presenting manifestation of HIV infection in an Indian. Indian J Dermatol Venereol Leprol. 2009;75:391-3.

2. Solivetti FM, Elia F, Latini A, Cota C, Cordiali-Fei P, Di Carlo A. AIDS-Kaposi Sarcoma and Classic Kaposi Sarcoma: are different ultrasound patterns related to different variants? J Exp Clin Cancer Res. 2011;30:40.

3. Mohanna S, Maco V, Gown A, Morales D, Bravo F, Gotuzzo E. Is classic Kaposi's sarcoma endemic in Peru?: report of a case in an indigenous patient. Am J Trop Med Hyg. 2006;75:324-6.

4. Kaposi M. Idiopathisches multiples Pigmentsarkom der Haut. Arch Dermatol Syph. 1872;4:265-73.

5. Beral V, Peterman TA, Berkelman RL, Jaffe HW. Kaposi's sarcoma among persons with AIDS: a sexually transmitted infection. Lancet. 1990;335:123-8.

6. Freidman-Kien AE, Laubenstein LJ, Rubinstein P, BuimoviciKlein E, Marmoa M, Stahl R, et al. Disseminated Kaposi sarcoma in young homosexual men. Ann Intern Med. 1982;96:693-700.

7. Hymes KB, Cheung T, Greene JB, Prose NS, Marcus A, Ballard H, et al. Kaposi's sarcoma in homosexual men-a report of eight cases. Lancet. 1981;2:598-600.

Copyright by Sanjay N. Agrawal, et al. This is an open access article distributed under the terms of the Creative Commons Attribution License, which permits unrestricted use, distribution, and reproduction in any medium, provided the original author and source are credited. 